\title{
Molecular diagnosis of Pseudoterranova decipiens s.s in human, France
}

\author{
Julie Brunet ${ }^{1,2^{*}}$, Bernard Pesson ${ }^{1}$, Maude Royant ${ }^{3}$, Jean-Philippe Lemoine ${ }^{1}$, Alexander W. Pfaff ${ }^{1,2}$, \\ Ahmed Abou-Bacar ${ }^{1,2}$, Hélène Yera ${ }^{4}$, Emilie Fréalle ${ }^{5}$, Jean Dupouy-Camet ${ }^{4}$, Gema Merino-Espinosa ${ }^{6}$, \\ Magdalena Gómez-Mateos ${ }^{6}$, Joaquina Martin-Sanchez ${ }^{6}$ and Ermanno Candolfi, ${ }^{1,2}$
}

\begin{abstract}
Background: Anisakis and Pseudoterranova are the main genera involved in human infections caused by nematodes of the Anisakidae family. Species identification is complicated due to the lack of differential morphological characteristics at the larval stage, thus requiring molecular differentiation. Pseudoterranova larvae ingested through raw fish are spontaneously eliminated in most cases, but mechanical removal by means of endoscopy might be required. To date, only very few cases of Pseudoterranova infection have been reported in France.

Case presentation: A 19-year-old woman from Northeastern France detected, while brushing her teeth, a larva exiting through her mouth. The patient who presented with headache, diarrhea, and abdominal cramps reported having eaten baked cod. The worm was a fourth-stage larva with a size of $22 \times 0.9 \mathrm{~mm}$, and molecular biology identified it as Pseudoterranova decipiens sensu stricto (s. s.). In a second P. decipiens infection case, occurring a few months later, a worm exited through the patient's nose after she had eaten raw sea bream.

Conclusion: These two cases demonstrate that Pseudoterranova infection is not uncommon among French patients. Therefore, molecular techniques should be more widely applied for a better characterization of anisakidosis epidemiology in France.
\end{abstract}

Keywords: Pseudoterranova decipiens, Anisakidae, Nematode, Molecular identification, Human infection, France

\section{Background}

Several helminth parasites of fish can infect humans, the most common genus being Anisakis, usually A. simplex s.s and $A$. pegreffii and less commonly Pseudoterranova and Contracaecum genera. Anisakidosis is encountered worldwide, though its prevalence is higher in countries where fish is primarily consumed raw. About 20,000 cases of anisakidosis have been reported worldwide, most of them in Japan [1-3]. Pseudoterranova decipiens (P. decipiens) is the second most common Anisakidae found in humans $[1,4]$. While rare in Europe, this nematode species is more frequently found in North America, Japan, Korea, and

\footnotetext{
* Correspondence: jbrunet@unistra.fr

'Laboratoire de Parasitologie et de Mycologie Médicale, Plateau Technique de Microbiologie, Hôpitaux Universitaires de Strasbourg, 1 place de l'Hôpital, BP 426F-67091 Strasbourg cedex, France

${ }^{2}$ Institut de Parasitologie et Pathologie Tropicale, EA 7292, Fédération de Médecine Translationnelle, Université de Strasbourg, 3 rue Koeberlé, F-67000 Strasbourg, France

Full list of author information is available at the end of the article
}

Chile [5-9]. A number of sibling species belong to this $P$. decipiens complex that is genetically, though not morphologically, distinguishable [10].

Adult of $P$. decipiens are mainly found in the gastrointestinal tract of pinnipeds (seals, sea lions, and walruses) that serve as definitive hosts [1, 4], while planktonic or benthic crustaceans act as intermediate hosts. Several fish species (natural second intermediate paratenic hosts) can be infected by third-stage larvae of $P$. decipiens, particularly Pacific cod, red snapper, hake, and Pacific halibut. A P. decipiens prevalence of up to $55 \%$ in Baltic cod was reported in the Southern Baltic Sea $[1,9,11]$. Encapsulated larvae reside mainly in visceral organs and peritoneal cavity of the fish, but some may migrate into the musculature [2].

Human infection is the result of accidental ingestion of the third-stage larvae present in viscerae or muscles of a wide range of marine fish or squids. Raw, undercooked, or 
marinated fish is a source of human contamination. In humans, the larvae do not develop into adult worms [1-4].

From 2010 to 2014, 19 cases of anisakidosis were reported in France, but this figure is probably underestimated in view of the parasite's high prevalence in fish [12]. The incidence of pseudoterranovosis in France has not yet been properly assessed as species diagnosis is rarely made, yet at least two cases have been reported following cod ceviche and raw coalfish consumption [13, 14].

Although humans are accidental hosts for this nematode parasite in which they cannot complete its life cycle, $P$. decipiens may cause serious disease. Symptoms usually appear 1-7 $\mathrm{h}$ after ingestion [4]. Then, the infection tends to be mostly asymptomatic, and larvae are usually coughed up by patients $36 \mathrm{~h}$ to 7 days following ingestion. Associated nausea and foreign body sensation between the teeth were also reported $[1,5,8,15,16]$.

Rare cases of invasive pseudoterranovosis may occur in humans. Larvae mostly penetrate the gastric mucosa, commonly causing severe epigastric pain. Larvae are extracted via endoscopy, resulting in rapid pain relief $[7,14,17]$.

We have reported herein two cases of pseudoterranovosis that molecular biology identified as $P$. decipiens s.s.

\section{Case presentation}

A 19-year-old woman living in Strasbourg (Northeastern France) complained of headache, diarrhea, asthenia, anorexia, and abdominal cramps having lasted for 15 days. The symptoms started after she had consumed baked cod. Two nematode larvae were spontaneously expelled via the mouth while she was brushing her teeth. The patient had an unremarkable medical history, and had not recently traveled abroad. The patient's discomfort improved after worm expulsion, and gastroscopy proved negative. The patient was treated with albendazole $800 \mathrm{mg} /$ day for 5 days.

Stool examination and blood analysis were all normal without eosinophilia. Serology was negative for Trichinella spiralis, Strongyloides stercoralis, Ascaris lumbricoides, and Toxocara canis.

Anisakis serology was also negative. IgG titers against Anisakis sp. were estimated at 1:50 $(<1: 100)$ using an own laboratory-developed Immunofluorescence assay (Parasitology-Mycology laboratory, Hôpital Cochin). Detection of anti-Anisakis antibodies using immunoelectrophoresis was negative and IgE titres against Anisakis sp. (p4) were at $<0.1 \mathrm{kUa}$ using ImmunoCAP (Phadia, France) (Parasitology-Mycology laboratory, Lille University hospital center). No IgE against cod were detected by means of ImmunoCAP.

The larva was brought to the Parasitology department of Strasbourg University Hospital for further characterization. The parasite was $22 \mathrm{~mm}$ long and $0.9 \mathrm{~mm}$ large with three anterior lips without any boring tooth (Figure 1). Morphological characteristics were a clearly visible esophagus and ventriculus, with a terminal tiny point (Figure 2). The parasite was morphologically characterized as a fourth-stage Anisakidae larva and submitted for molecular species identification at the department of Parasitology, University of Granada, Spain.

DNA was extracted from a roundworm portion using the commercial kit RealPure kit for genomic DNA extraction (REAL), following mechanical rupture of parasite tissue using a pestle and repeated freezing/thawing cycles in liquid $\mathrm{N}_{2}$. The precipitated pellet was resuspended in $20 \mu \mathrm{L}$ of deionized water. For genetic identification of the larva, polymerase chain reaction of the ribosomal fragment ITS1-5,8S-ITS2 was carried out with primers NC5 (forward): 5' GTAGGTGAA CCTGCGGAAGGATCATT $3^{\prime}$ and NC2 (reverse) 5' TTAGTTTCTTTTCCTCCGCT 3' using programming described in 1998 by Zhu et al. [18]. The expected size of the amplified fragment was approximately $1000 \mathrm{bp}$. As controls, two specimens previously identified by the same technique as $A$. pegreffii and $A$. simplex s.s., were used respectively [19]. PCR products were run on gels prior to digestion in order to verify the amplification process's success.

First, restriction fragment length polymorphism (RFLP) was performed independently with two restriction enzymes, TaqI (5'...T $\downarrow$ CGA...3') and HinfI ( $5^{\prime}$...G $\downarrow$ ANT.... $\left.3^{\prime}\right)$ Fast Digest (Thermo Sciencific) at $65{ }^{\circ} \mathrm{C}$ and $37{ }^{\circ} \mathrm{C}$, respectively for $10 \mathrm{~min}$, using a final enzyme concentration of $0.5 \mathrm{U} / \mu \mathrm{L}$. The results were visualized through electrophoresis on a $3 \%$ agarose gel. The band pattern collected from the roundworm differed from A. simplex s.s. and A. pegreffii controls.

For comparative sequence analysis, the PCR amplification product was purified using the Zymoclean Gel

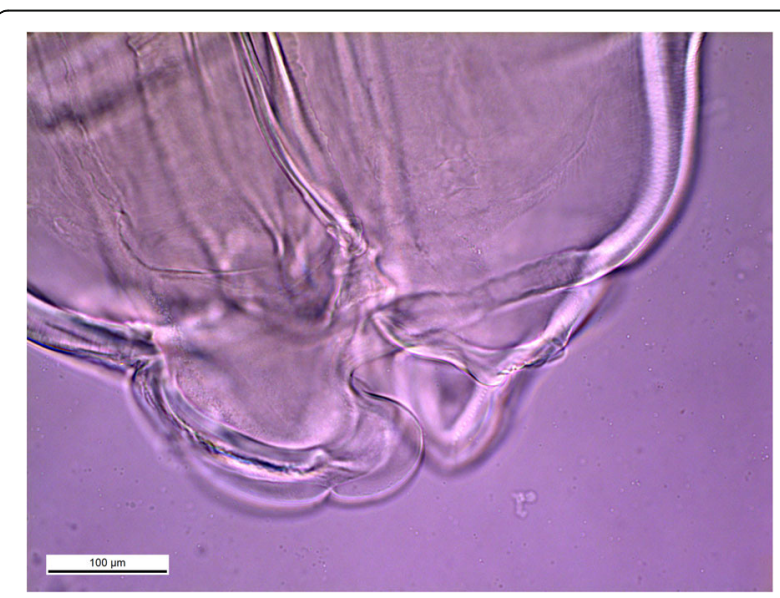

Fig. $1 P$. decipiens sensu stricto anterior region with three anterior lips without any boring tooth 


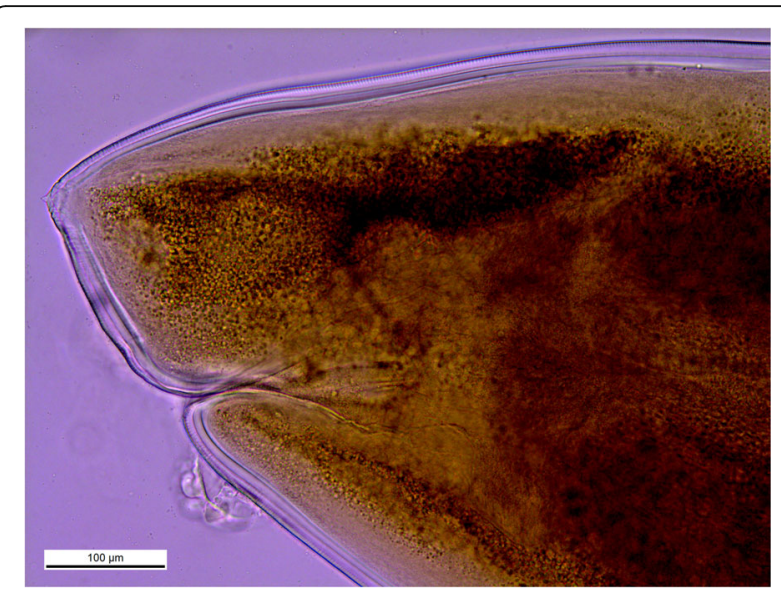

Fig. 2 P. decipiens sensu stricto tail with mucron

DNA Recovery Kit (Zymo Research), and then directly sequenced in both directions using the same primers as for DNA amplification. The sequences were edited and aligned using Clustal-X 1.81 software. Subsequently, BLAST software was employed to compare this sequence with a sequence library in order to identify similar sequences. As shown in Fig. 3, two identical sequences of $P$. decipiens s.s. from Denmark (GenBank accession number KM273087.1) and Norway (GenBank accession number JQ673262.1) showed a 99\% similarity with our sequence. The alignment has been detailed in Fig. 3.

In a second infection case occurring a few months later, a worm exited through the patient's nose after she had eaten raw sea bream. The larva was morphological and molecularly identical to the previous case being identified as $P$. decipiens s.s.

\section{Conclusion}

Incidence of Pseudoterranova infection in France has not yet been assessed; owing to the lack of specific symptoms, the condition is most likely underdiagnosed. In most of the described cases, infections refer to Pseudoterranova sp., whereas at least eight sibling species of Pseudoterranova were genetically differentiated with distinct geographical and host ranges: P. decipiens s.s., $P$. kogiae, P. ceticola, P. decipiens E, P. cattani, P. azarasi, P. krabbei, and P. bulbosa, which are morphologically indistinguishable [20]. In our cases, molecular biology allowed us to precisely identify the fourth-stage larvae as $P$. decipiens s.s.

$P$. decipiens s.s. is principally located in the Arctic and subarctic regions. Adult stages are frequently found in common seal, grey seal, and Phocidae. Larval forms are mostly encountered in Gadidae fish species like coalfish or cod [10].
There is a distinct difference in the clinical syndromes of human pseudoterranoviasis between those encountered in Japan and the USA. In Japan, the disease is rather severe, whereas in the USA, the condition is milder and without clear symptoms attributable to gastrointestinal invasion [21]. Whether the clinical manifestations differ among $P$. decipiens species are still to be determined, partly due to only tentative species identification in most reported cases. However, P. decipiens larvae seem to be less invasive than those of the Anisakis simplex complex [1, 15]. Absent severe gastric symptoms were reported in $P$. azarasi and $P$. cattani infections $[15,16]$. For $P$. azarasi infection, which applied to our patient, morphological diagnosis was made based on orally expelled fourth-stage larvae, associated to the lack of a boring tooth [16]. Third- or fourth-stage Pseudoterranova larvae can cause human infections [5]. Third-stage larvae invade gastric mucosa where they molt to fourth-stage larvae, without ever reaching the adult stage in humans $[5,14,16]$. For A. simplex in humans, the parasite passes from third- to fourth-stage larva within 3 to 4 days following ingestion [22]. To date, only two cases of human infection caused by $P$. decipiens larvae have been reported in France. In the first case, reported in 1996, a 40-year-old woman presented with epigastric pain. A larva was removed from the epigastric mucosa via gastroscopy, and morphologically identified as fourthstage larva of $P$. decipiens sp. The second case, reported in 2014, concerned a 25-year-old woman. A larva was expectorated by the patient and identified as Pseudoterranova sp. [13, 14].

Clinical diagnosis proves to be difficult due to nonspecific symptoms. Diagnosis is primarily made when the patient coughs up or vomits the worm. Endoscopic examination may be useful, though gastric pseudoterranovosis is commonly misdiagnosed as a peptic ulcer. Interpretation of immunological tests is often difficult owing to cross-reactivity with antigens from closely related nematode species like Ascaris or Toxocara $[1,4]$. In the rare event of Pseudoterranova infection detected by Anisakis serology, the test was negative for IgG (1:50 using own laboratory-developed IFA) yet positive for IgE (1.4kUa ImmunoCAP) [13]. In this case, and contrary to our cases, the patient suffered from symptoms a few hours after having consumed contaminated raw fish.

Molecular biology analysis, while rarely carried out, has nevertheless epidemiological usefulness to determine the specific species within the genus. Since 2015, two cases of anisakidosis have been diagnosed at Strasbourg University Hospital, with $P$. decipiens identified in both cases. In the second case, the patient spontaneously expelled one larva through the nose after having eaten raw sea bream. 


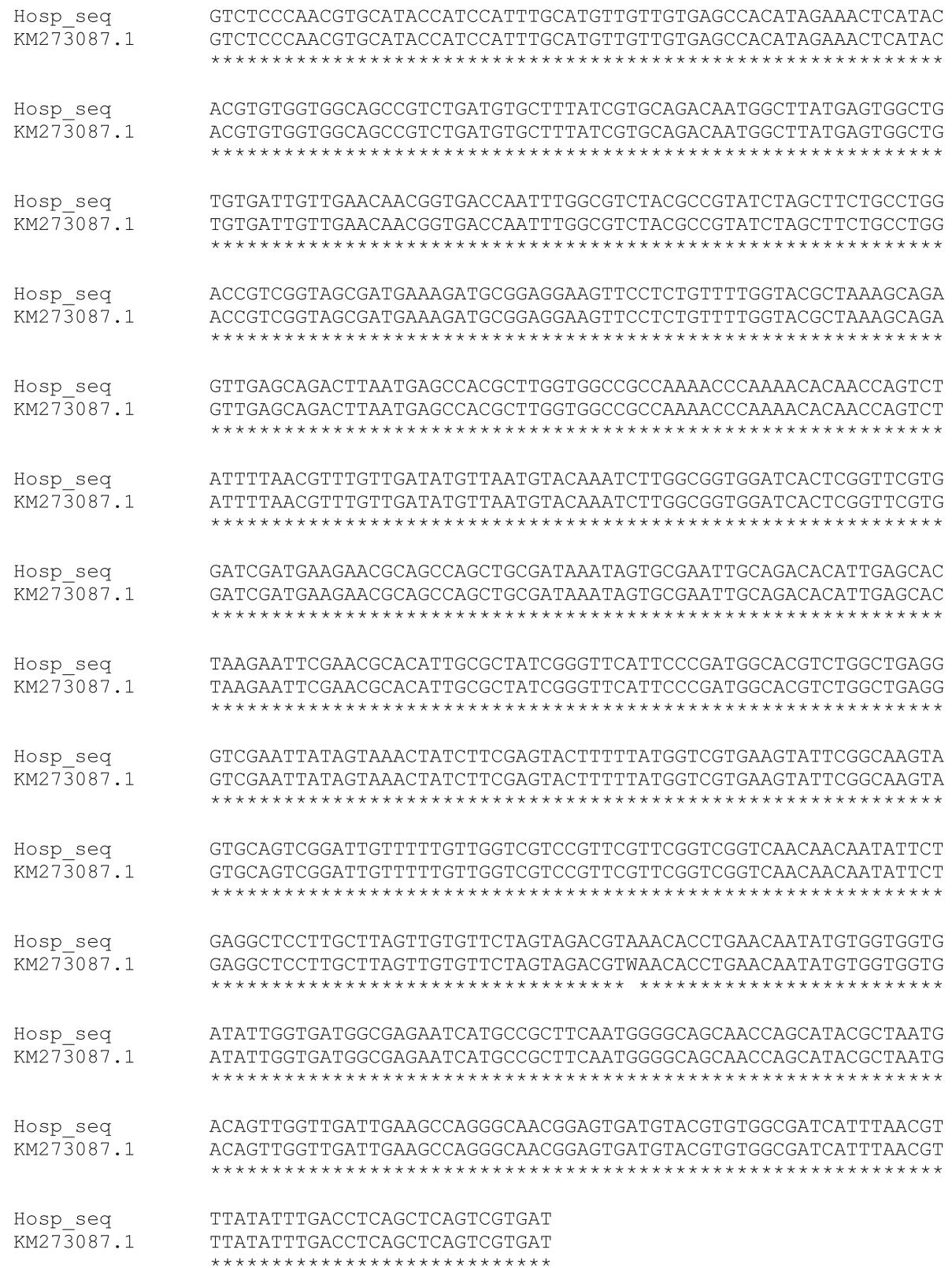

Fig. 3 Sequence alignment detailed of $P$. decipiens sensu stricto of this case

Extraction is the preferred treatment if the larva is not spontaneously coughed up. In most cases, abdominal discomfort gradually decreases following worm removal. Several studies suggest that albendazole $(400-800 \mathrm{mg} /$ day for 6-21 days) may result effective $[1,23]$.

No specific pharmacological treatment exists to effectively kill live larvae in seafood, and the best protection consists of individual prevention. The infection risk is clearly related to traditions of consuming raw, lightly cooked, or marinated fish (sushi, gravlax, ceviche, etc.), even more so if the fish is eaten whole. The contamination risk can be reduced by appropriate preparation of fish and squid. Larvae are killed by temperatures higher than $60{ }^{\circ} \mathrm{C}$ over at least $1 \mathrm{~min}$, freezing at $-20^{\circ} \mathrm{C}$ for 7 days, or freezing at $-35^{\circ} \mathrm{C}$ for at least $15 \mathrm{~h} \mathrm{[1-4]}$.

\section{Abbreviations}

RFLP: restriction fragment length polymorphism

\section{Author contributions}

$\mathrm{JB}, \mathrm{BP}, \mathrm{AA}, \mathrm{HY}, \mathrm{EF}$, JDC, JMS, and EC were responsible for data analysis and management, as well as writing the manuscript. JPL, AWP helped with manuscript corrections. GME and MGM carried out the molecular analysis of the larvae. MR conducted this clinical investigation and helped with manuscript corrections. All authors read and approved the final manuscript. 


\section{Ethics and consent to participate}

Not applicable.

\section{Funding}

No funding was obtained for this study.

\section{Availability of data and materials}

All the data supporting our findings is contained within the manuscript.

\section{Competing interests}

The authors declare that they have no competing interests.

\section{Consent for publication}

Written informed consent was obtained from the patient for publication of this case report and any accompanying images. A copy of this consent is available for review by the Editor of this journal.

\section{Author details}

'Laboratoire de Parasitologie et de Mycologie Médicale, Plateau Technique de Microbiologie, Hôpitaux Universitaires de Strasbourg, 1 place de l'Hôpital, BP 426F-67091 Strasbourg cedex, France. ${ }^{2}$ Institut de Parasitologie et Pathologie Tropicale, EA 7292, Fédération de Médecine Translationnelle, Université de Strasbourg, 3 rue Koeberlé, F-67000 Strasbourg, France. ${ }^{3}$ Service des consultations externes, Hôpitaux Universitaires de Strasbourg, 1 place de I'Hôpital, BP 426F-67091 Strasbourg cedex, France. ${ }^{4}$ Service de Parasitologie-Mycologie, Hôpital Cochin, Hôpitaux Universitaires Paris Centre, Assistance Publique Hôpitaux de Paris, Université Paris Descartes, 27 rue du Faubourg St Jacques, F-75015 Paris, France. ${ }^{5} \mathrm{CHU}$ Lille, Laboratoire de Parasitologie-Mycologie et Université de Lille, CNRS, Inserm, Institut Pasteur de Lille, U1019 - UMR 8204 - CIIL - Center for Infection and Immunity, Lille, France. ${ }^{6}$ Departamento de Parasitología, Facultad de Farmacia, Universidad de Granada, Campus Universitario de Cartuja s, /n 18071 Granada, Spain.

Received: 4 July 2016 Accepted: 25 May 2017

Published online: 06 June 2017

\section{References}

1. Hochberg NS, Hamer DH. Anisakidosis: perils of the deep. Clin Infect Dis. 2010:51:806-12.

2. Fréalle E, Gay M, Touabet N, Seesao Y, Dutoit E, Yera H, Certad G, DupouyCamet J, Viscogliosi E, Aliouat-Denis CM. L'anisakidose, une helminthose humaine aux manifestations allergiques émergentes. Feuillets de biologie. 2016; 328:27-38.

3. Shamsi S, Butcher AR. First report of human anisakidosis in Australia. Med J Aust. 2011;21(194):199-200.

4. Chai JY, Darwin Murrell K, Lymbery AJ. Fish-borne parasitic zoonoses: status and issues. Int J Parasitol. 2005;35:1233-54.

5. Mercado $R$, Torres $P$, Munoz $V$, Apt W. Human infection by Pseudoterranova decipiens (Nematoda, Anisakidae) in Chile: report of seven cases. Mem Inst Oswaldo Cruz. 2001:96:653-5.

6. Yu JR, Seo M, Kim YW, Oh MH, Sohn WM. A human case of gastric infection by Pseudoterranova decipiens larva. Korean J Parasitol. 2001;39:193-6.

7. Shudo R, Yazaki Y, Yamada H, Sugawara K, Takahashi K. Infection with a black Pseudoterranova decipiens. Gastrointest Endosc. 2002;56:110.

8. Na HK, Seo M, Chai JY, Lee EK, Jeon SM. A case of anisakidosis caused by Pseudoterranova decipiens larva. Korean J Parasitol. 2013;51:115-7.

9. Mehrdana F, Bahlool QZ, Skov J, Marana MH, Sindberg D, Mundeling M, et al. Occurrence of zoonotic nematodes Pseudoterranova decipiens, Contracaecum osculatum and Anisakis simplex in cod (Gadus morhua) from the Baltic Sea. Vet Parasitol. 2014;205:581-7.

10. Mattiucci S, Nascetti G. Advances and trends in the molecular systematics of anisakid nematodes, with implications for their evolutionary ecology and host-parasite co-evolutionary processes. Adv Parasitol. 2008;66:47-148.

11. Audicana MT, Kennedy MW. Anisakis simplex: from obscure infectious worm to inducer of immune hypersensitivity. Clin Microbiol rev. 2008;21:360-79.

12. Dupouy-Camet J, Touabet-Azouzi N, Fréalle E, Van Cauteren D, Yera H, Moneret-Vautrin A. Incidence de I'anisakidose en France. Enquête rétrospective 2010-2014. Bull Epidémiol Hebd. 2016;5-6:64-70.

13. Dupouy-Camet J, Gay M, Bourgau O, Nouchi A, Leger E, Dei-Cas E. Oesophageal localization: a rare complication of anisakidosis due to Pseudoterranova. Presse med. 2014;43:81-3.
14. Pinel C, Beaudevin M, Chermette R, Grillot R, Ambroise-Thomas P. Gastric anisakidosis due to Pseudoterranova decipiens larva. Lancet. 1996;347:1829.

15. Weitzel T, Sugiyama H, Yamasaki H, Ramirez C, Rosas R, et al. (2015) human infections with Pseudoterranova cattani nematodes, Chile. Emerg Infect Dis. 1996;21:1874-5

16. Arizono N, Miura T, Yamada M, Tegoshi T, Onishi K. Human infection with Pseudoterranova azarasi roundworm. Emerg Infect Dis. 2011;17:555-6.

17. Sohn WM, Seol SY. A human case of gastric anisakiasis by Pseudoterranova decipiens larva. Korean J Parasitol. 1994;32:53-6.

18. Zhu X, Gasser RB, Podolska M, Chilton NB. Characterisation of anisakid nematodes with zoonotic potential by nuclear ribosomal DNA sequences. Int J Parasitol. 1998;28:1911-21.

19. Martín-Sánchez J, Artacho-Reinoso ME, Díaz-Gavilán M, Valero-López A. Structure of Anisakis simplex s.L. populations in a region sympatric for $A$. pegreffii and A. simplex s.S. Absence of reproductive isolation between both species. Mol Biochem Parasitol. 2005;2005(141):155-62.

20. Timi JT, Paoletti M, Cimmaruta R, Lanfranchi AL, Alarcos AJ, Garbin L, et al. Molecular identification, morphological characterization and new insights into the ecology of larval Pseudoterranova cattani in fishes from the argentine coast with its differentiation from the Antarctic species, $P$. decipiens sp. E (Nematoda: Anisakidae). Vet Parasitol. 2014;199:59-72.

21. Zhu XQ, .D'Amelio S, Palm HW, Paggi L, George-Nascimento $M$, ,Gasser RB. SSCP-based identification of members within the Pseudoterranova decipiens complex (Nematoda: Ascaridoide:Anisakidae) using genetic markers in the internal transcribed spacers of ribosomal DNA. Parasitology2002; 124: 613-623.

22. Mf R, Mascaró C, Fernandez C, Luque F, Sanchez Moreno M, Parras L, et al. Acute intestinal anisakiasis in Spain: a fourth-stage Anisakis simplex Larva. Mem Inst Oswaldo Cruz. 1999;94(6):823-6.

23. Pacios E, Arias-Diaz J, Zuloaga J, Gonzalez-Armengol J, Villarroel P, Balibrea JL. Albendazole for the treatment of anisakiasis ileus. Clin Infect Dis. 2005:41:1825-6.

\section{Submit your next manuscript to BioMed Central and we will help you at every step:}

- We accept pre-submission inquiries

- Our selector tool helps you to find the most relevant journal

- We provide round the clock customer support

- Convenient online submission

- Thorough peer review

- Inclusion in PubMed and all major indexing services

- Maximum visibility for your research

Submit your manuscript at www.biomedcentral.com/submit
BioMed Central 